\title{
Corrigendum: Transcriptome Analysis Showed a Differential Signature Between Invasive and Non-invasive Corticotrophinomas
}

\author{
Leonardo Jose Tadeu de Araújo 1,2, Antonio Marcondes Lerario 1,3, Margaret de Castro ${ }^{4}$, \\ Clarissa Silva Martins ${ }^{4}$, Marcello Delano Bronstein ${ }^{1,5}$, Marcio Carlos Machado ${ }^{1,5,6}$, \\ Ericka Barbosa Trarbach ${ }^{7}$ and Maria Candida Barisson Villares Fragoso ${ }^{1,6 *}$ \\ ${ }^{1}$ Laboratory of Hormones and Molecular Genetics LIM-42, University of São Paulo Medical School, São Paulo, Brazil, \\ ${ }^{2}$ Laboratory of Quantitative Pathology, Center of Pathology, Adolfo Lutz Institute, São Paulo, Brazil, ${ }^{3}$ Division of Metabolism, \\ Endocrinology and Diabetes, University of Michigan, Ann Arbor, MI, United States, ${ }^{4}$ Internal Medicine Department, Ribeirao \\ Preto Medical School, University of São Paulo, Ribeirao Preto, Brazil, ${ }^{5}$ Neuroendocrine Unit, Division of Endocrinology and \\ Metabolism, University of São Paulo Medical School, São Paulo, Brazil, ${ }^{6}$ Endocrinology Service, AC Cancer Center, \\ São Paulo, Brazil, ' Laboratory of Cellular and Molecular Endocrinology LIM-25, University of São Paulo Medical School, \\ São Paulo, Brazil
}

Keywords: Cushing's disease, gene expression, neuroendocrine tumors, microarray, anterior pituitary

\section{A Corrigendum on}

Transcriptome Analysis Showed a Differential Signature Between Invasive and Non-invasive Corticotrophinomas

OPEN ACCESS

Edited and reviewed by: Nienke Biermasz,

Leiden University, Netherlands

${ }^{*}$ Correspondence: Maria Candida Barisson Villares Fragoso

maria.villares@hc.fm.usp.br

Specialty section

This article was submitted to Pituitary Endocrinology,

a section of the journal

Frontiers in Endocrinology

Received: 23 May 2019 Accepted: 02 August 2019 Published: 22 August 2019

Citation:

de Araújo LJT, Lerario AM, de Castro M, Martins CS, Bronstein MD, Machado MC

Trarbach EB and Villares Fragoso MCB (2019) Corrigendum:

Transcriptome Analysis Showed a Differential Signature Between Invasive and Non-invasive Corticotrophinomas.

Front. Endocrinol. 10:567.

doi: 10.3389/fendo.2019.00567 by de Araújo, L. J. T., Lerario, A. M., de Castro, M., Martins, C. S., Bronstein, M. D., Machado, M. C., et al. (2017). Front. Endocrinol. 8:55. doi: 10.3389/fendo.2017.00055

In the original article, there was an error. We stated that USP8 genetic abnormalities were not identified in DNA from tumor samples analyzed by microarray technology.

A correction has been made to Abstract, Paragraph Number 1, Lines 18-19.

Somatic mutations in USP8 were also investigated and mutations were identified in six cases.

A correction has been made to Results, Paragraph Number 1.

Before microarray analysis, we performed the screening for mutations in USP8 in our patients, and somatic variants were found in patients \#2 and \#5 (p.Ser718Pro), \#4 (p.Ser718Cys), patients $\# 3$ and \#6 (p.Pro720Arg), and \#9 (p.Pro720Gln). Both mutations were found in heterozygosis and have been previously described $(17,18)$.

A correction has been made to Discussion, Paragraph Number 1.

In the microarray study cohort, we identified six USP8 mutations in 12 samples (50\%). In the patients included in the validation study, we could identify somatic USP8 mutations in 5 (non-invasive corticotrophinomas) out of 18 patients (27.7\%). According to Reincke et al. (17) and Perez-Rivas et al. (18), these mutations occur in $\approx 36 \%$ of patients with CD. Interestingly, the presence of USP8 mutations did not interfere in the transcriptome expression analysis results comparing invasive vs. non-invasive tumors and in its validation study.

The authors apologize for this error and state that this does not change the scientific conclusions of the article in any way. The original article has been updated.

Copyright (C) 2019 de Araújo, Lerario, de Castro, Martins, Bronstein, Machado, Trarbach and Villares Fragoso. This is an open-access article distributed under the terms of the Creative Commons Attribution License (CC BY). The use, distribution or reproduction in other forums is permitted, provided the original author(s) and the copyright owner(s) are credited and that the original publication in this journal is cited, in accordance with accepted academic practice. No use, distribution or reproduction is permitted which does not comply with these terms. 